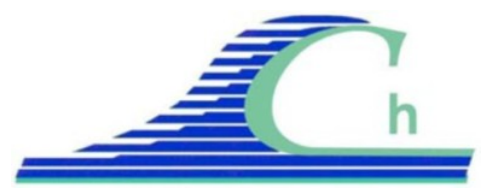

XII ${ }^{\text {ìmes }}$ Journées Nationales Génie Côtier - Génie Civil

Cherbourg, 12-14 juin 2012

DOI:10.5150/jngcgc.2012.034-M @ Editions Paralia CFL

disponible en ligne - http://www.paralia.fr - available online

\title{
Shoreline and upper beach dynamics under extreme events: the KUNSHEN experiment (Wan-tzu-liao barrier, Taiwan)
}

\author{
Samuel MEULÉ ${ }^{1,2}$, Lucie CAMPMAS ${ }^{3}$, Frédéric BOUCHETTE ${ }^{3,8}$, \\ Jiing-Yih LIOU ${ }^{4}$, François SABATIER ${ }^{1}$, Damien SOUS ${ }^{6}$, Georgios SYLAÏOS ${ }^{5}$, \\ Vincent REY ${ }^{6}$, Ying-Chih WU ${ }^{4}$, Tsung-Yi LIN ${ }^{7}$, Hwung-Hweng HWUNG ${ }^{4}$
}

1. CEREGE UMR 6635, OSU PYTHEAS, CNRS/Aix Marseille Université, Aix-En-Provence, France. meule@cerege.fr

2. LIA-ADEPT (LIA CNRS/NCS 536) France/Taiwan. http://www.lia-adept.org

3. GLADYS/SOLTC/OREME Géosciences-M, CNRS/ UM2, Montpellier, France.

4. National Cheng Kung University, No.1, University Road, Tainan City 701, Taiwan.

5. Department of Environmental Engineering, University of Thrace, Greece.

6. LSEET UMR 6017, Université du Sud Toulon-Var, 83957 La Garde Cedex, France.

7. National Taiwan Normal University, Taipei 106, Taiwan, R.O.C.

8. METOS, Forskning Center, University of Oslo, Blindern, Norway.

\begin{abstract}
:
Barrier island hydro-morphodynamics driven by typhoon events are the major concern of the project KUNSHEN (2011-2014). It aims at providing for a deep understanding of the peculiar dynamics of sand barriers where extreme events such as typhoons have a significant impact. We present the campaigns and the protocols achieved and planned in the project, on the Wan-tzu-liao sand barrier, Cigu Lagoon, Tainan, Taiwan, from October 2011 to January 2012, during the winter storm season and during summer 2012 during the typhoon season. A set of current profilers are deployed along a cross shore transect at 7, 4 and 2 meters deep. On the Wan-tzu-liao sand barrier, 3 columns of 3 pressiometers are deployed to survey the submersion. In the same time, morphological surveys are performed on the sand barrier with DGPS to analyse any change in the shoreline position, the beach slope, and the dynamics of sand beach features. A very preliminary analysis on these on-going field surveys suggests that the word "extreme" refers more to the consequence of the forcing on the sand barrier than the intensity of the forcing itself. The strategy developed in this first step will be refined to survey the next typhoon season, from May 2012 to October 2012.
\end{abstract}

Keywords:

Extreme events - Submersion - Typhoon - Taiwan

\section{Introduction}

Barrier island hydro-morphodynamics driven by typhoon events are the major concern of the KUNSHEN project (2011-2014). The project aims at providing for an up-to-date 
and deep understanding of the dynamics of sand barriers, of their formation and their destruction under extreme events such as typhoons. This paper focuses on the methodological approach. Two main field campaigns are planned during the project. The first campaign was conducted during winter season from November 2011 to January 2012. The second campaign will be conducted during summer season 2012, when typhoons are predicted to landing and seriously affecting Cigu area (Tainan County, Taiwan). In this paper, we present the Cigu system, the methodology used to deploy the equipment under extreme events and the questions that may be tackled thanks to these in-situ field surveys.

\section{Hydro-morphological settings of the Cigu system}

\subsection{The Cigu lagoon and the taiwanese context}

The Cigu sand barrier (figure 1) is located in the Cigu and Zengwun river delta plains, in the vicinity of Tainan city, south-western Taiwan. Along this sandy coast opened to the West on the $170 \mathrm{~km}$ wide Taiwan strait, well-developed brackish shallow water bodies occur. They are separated from the open sea by km-long barrier islands or sand spits. The nearshore (and lagoon) morphology is clearly different from that of Eastern Taiwan, where the coast displays a steeper slope, no lagoon, and pocket beaches delimited by well-formed rocky headlands. The south-western barrier islands are developed on a trailing-edge coast. A high lifting rate due to the continent-arc collision generates a high erosion rate in the watershed. Subsequently, high sedimentation should be observed along the coast. However the Cigu littoral system shows evidences of coastal erosion.

\subsection{Cigu littoral dynamics}

The Cigu littoral system is formed by: (1) a shoreface with a nearshore slope of the order of 1:10 varying along the year according to sand bar dynamics. Existing monitoring of nearshore water depth shows current sand bar dynamics; (2) a 1-10 m high and 10-100 m wide sandy barrier (Wan-tzu-liao barrier); (3) the $8 \mathrm{~km}$ long and $3 \mathrm{~km}$ wide Cigu lagoon itself bounded by a highly anthropogenic zone to the East, mainly made of oyster culture, fish ponds and ancient salt fields delineated by dikes. Water depth in central Cigu lagoon is about 1-2 $\mathrm{m}$, and 4-5 $\mathrm{m}$ along some discrete channels dedicated to sailing. Cigu Lagoon is the largest remaining lagoon in the southwestern coast of Taiwan and the Wan-tzu-liao barrier is one of the two remaining natural barrier islands of Taiwan. Dune erosion and shoreline retreat on Wan-tzu-liao barrier have been monitored. Engineering structures built northward of the studied area may have intercepted the sediment sources for the barrier island.

The consequences are a decrease of the mean elevation and a land area shrinkage of the barrier. 


\section{XII ${ }^{\text {èmes }}$ Journées Nationales Génie Côtier - Génie Civil \\ Cherbourg, 12-14 juin 2012}

\section{$2.3 \underline{\text { Storm inlets }}$}

The barrier has been breached several times to form new tidal inlets (LIN et al., 2007). To the North, the low elevation tends to be vulnerable to the storm waves and the sand barrier does not display well-developed vegetation. Therefore, the sand barrier is cut by a set of inlets that encourage water flow between sea and lagoon driven predominantly by the semi-diurnal tide. One of them formed in 1999 after a major storm event. Breaches of the barrier island are more often since late 1999. Such coastal features result from combined effect of tide and over-topping of waves, leading to over-washes of the sand barrier and subsequent wash-over deposits in the lagoon. They highlight the shoreward displacement of the sand barrier. Southward, the sand barrier is cut by a permanent tidal inlet (Ding-Tou-Er inlet).
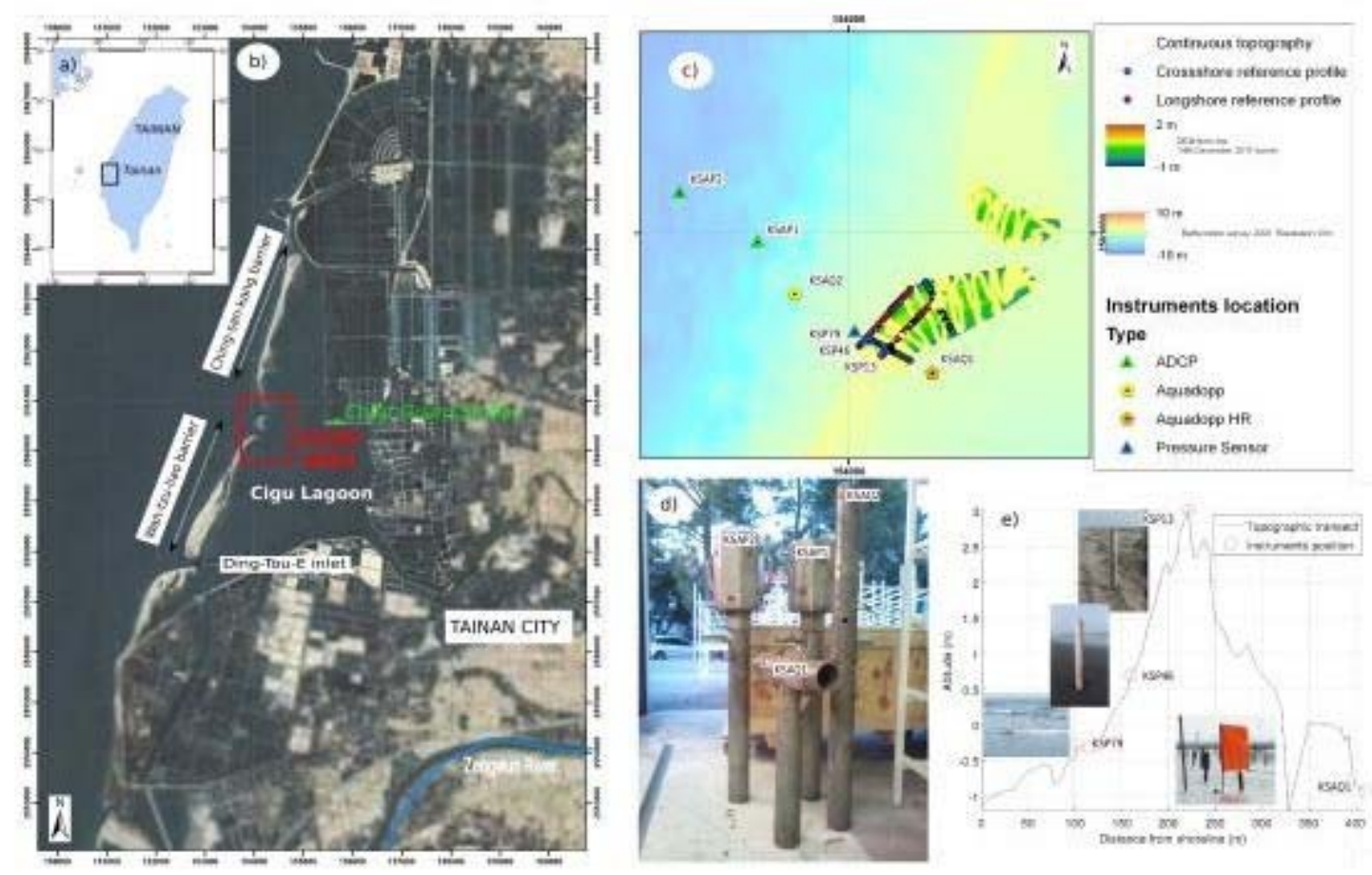

Figure 1. a)Taiwan Island. b) Study area location. c) Instruments location and altimetric survey strategy. d) Photography of frames. e) Location of the pressure sensors superimposed over a topographic survey.

Flood tidal delta may appear at Ding-Tou-Er inlet. Eolian sand dunes are 1-8 m high and covered of vegetation, including dense groves locally. Qualitative historical transformation of the morphology of the (a) Cigu lagoon and its former lagoons existed since the seventeenth century, (b) sand barrier has moved landward since mid twentieth century. However, no analysis of the architecture of sand barrier and lagoon deposits, as well as that of underlying deposits with geophysical surveys and/ or cores exist. 
Consequently, the formation and the Holocene (from 18 kyrs until now) evolution of Cigu system are unknown.

\subsection{Hydrodynamic settings of the Cigu system}

As Taiwan straddles the Tropic of Cancer, south-western Taiwan climate is subtropical, with a mean temperature of $16.5^{\circ}$ in January and $28^{\circ}$ in August. Winter season displays fair-weather wave and wind climates at sea, with occurrence of some moderate storms. Typhoon season hits in early summer to mid-autumn and strikes Taiwan's coasts strongly. Along the south-western coast where Cigu sand barrier lies, typhoons mainly propagate from the South between June to early July, and from the East later. Figure 2 represents the typhoon tracks over the year 2008. It shows that consequent number of typhoons may occurs in the study area. Consequently, Cigu system is exposed to a wide set of fair-weather and severe wave and wind conditions, including some of the most extreme meteorological events around the world.
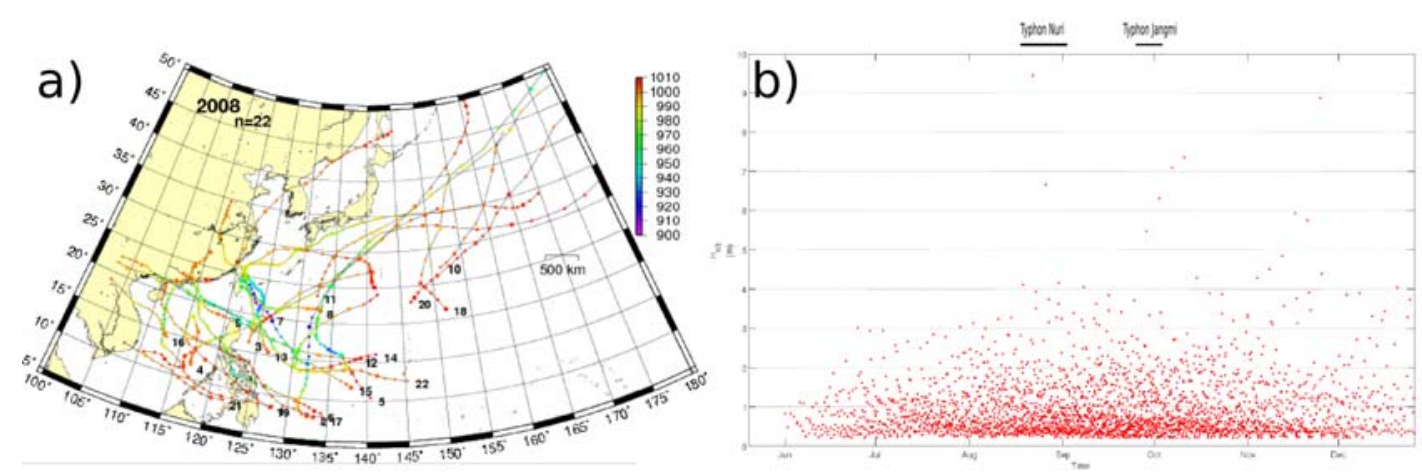

Figure 2. a) Typhoons track in 2008. b) Wave height during typhoon season from Dingtoue buoy at $18 \mathrm{~m}$ depth, $1.5 \mathrm{~km}$ seaward from the field area.

Weather observations from Tainan domestic airport and from the Dingtoue buoy (http://www.cwb.gov.tw/v6e) at $18 \mathrm{~m}$ of water depth, $1.5 \mathrm{~km}$ seaward from the field area will give the local meteorological forcings. A review of historic wind data from the Airport Station (eastern Cigu lagoon) was conducted for 2008. It was shown that winter winds are north-easterly, and summer winds are variable. Typical local wave climates seaward Cigu system can be derived from the Dingtoue directional wave buoy. Calculated spectra of wave energy distribution at this point show that during typhoon events, wave conditions depend on typhoon tracks (see figure 2a et b). Wave direction may vary from SW to NW. Typical observed wave heights and periods are of the order of $8 \mathrm{~m}$ and $12 \mathrm{~s}$ respectively. The highest wave height ever measured $(32.3 \mathrm{~m})$ was observed in North Taiwan at Gueishantao station (LIU et al., 2008) during typhoon Krosa (October $6^{\text {th }}$, 2007). Tidal range is about $1 \mathrm{~m}$ and water elevation was recorded at several points inside the lagoon. 


\section{XII ${ }^{\text {èmes }}$ Journées Nationales Génie Côtier - Génie Civil \\ Cherbourg, 12-14 juin 2012}

\section{Field survey protocols}

\subsection{Altimetric/bathymetric surveys}

Systematic altimetric surveys of the Cigu sand barrier are conducted at high frequencies with a RTK/ DGPS over the study area allowing an almost centimeter accuracy. The reference location will be located at the Coast Guard station (see figures 1a and 1b). All data are georeferenced in TWD97/TM2 zone 119, which is a Coordinate Reference System for Topographic and engineering survey in Taiwan. It was defined by information from National Land Surveying and Mapping Center. Special attention is paid to surveys done before and after typhoon events, so that typhoon-driven morphological changes on the sand barrier can be easily quantified. During the first field campaign (Nov. 2011 - Jan. 2012) a set of ten altimetric surveys were achieved. In the prospect of integrating altimeter data into models, the present study has pointed out a specific strategy. This strategy, illustrated by figure 1c, consists in : (1) a continuous topography, (2) 2 crosshore and 2 longshore reference profiles, (3) and profiles along some specific morphological features. The digital elevation model is therefore calculated using Delaunay (or Akima alternatively) spatial interpolation. Seaward, the determination of the morphological and sediment features are obtained from classical echosounding bathymetric surveys on the whole site. As a complement to field measurements, satellite imagery will be used to evaluate the variability of the lagoon through time and space. This methodological work constitutes a first step toward the understanding of the coastal dynamics of the Wan-tzu-liao barrier.

\subsection{Device frames to be deployed during typhoons}

An important goal of the projet is to develop specific frames adapted to the monitoring of hydrodynamics and sediment processes in shallow water under typical typhoon conditions. These frames should display: (1) the ability to resist to typhoon wave stresses, which means a deep and robust anchorage within the seabottom and/or a large amount of weights; We chose to insert $7 \mathrm{~m}$-length stainless tubes inside the sediment. Those tubes will be the anchor; (2) user-friendly connections, so that a simple diver can operate rapidly and easily; (3) on the frame and the equipments during poor weather conditions; We choose to develop specific frame-head connector adapted to the anchor. Figure 1d shows frame-head adapted for the RDI-ADCP, the Nortek-Aquadopp and the Nortek-ADV-OBS.

\section{3 $\underline{\text { Hydrodynamic surveys }}$}

The autonomous instrumented benthic frames were deployed between November 2011 and January 2012 along a crossshore section (see figure 1b and 1e) in order to get time series of physical forcing in the Cigu littoral, both in the nearshore zone, in the lagoon 
and on the sand barrier. This field campaign provides a set of data for the winter season. The second campaign in summer 2012 will provide the hydrodynamics for the typhoon season. Retrieval of the time series data will allow partners of the KUNSHEN project to investigate the following points : (1) Analysis of wave generation by winds; (2) Measurements of velocity profiles in the nearshore zone; (3) Measurements of the directional wave spectrum and wave characteristics; (4) Analysis of the wave propagation, dissipation, refraction, reflection; (5) Wave-wave energy transfer; (6) Analysis of the non-linear wave-current interaction; (7) Analysis of low frequency modes; (8) Interactions between surface and groundwater dynamics; (9) Sand porous media response to wave pressure forcing allowing evaluation of the sand barrier potential impact on sediment transport. Indeed, liquefaction process may play an important role in the sand transport process during the expected extreme events. (10) Identification and measurements of other forcing mechanisms (tide, fresh water input).

\section{Discussion}

The data processing of the winter campaign is not achieved and cannot be correctly presented here. However, a very preliminary comparison of data from Taiwan and similar data from historical hydro-morphodynamic surveys along the northernmost Mediterranean Sea (http://www.soltc.org) highlights an interesting question. Indeed, we notice that the word "extreme" is somewhat subjective. In some cases, an extreme meteorological coastal event clearly refers to typhoons, hurricanes or at least to tropical storms of class IV. But, in many other cases, people call "extreme" an event that corresponds to moderate storms with respect to hydrodynamics and wind forcings. This highlights the fact that "extreme" refers more to the impact of the meteorological event than to the features and to the intensity of the phenomenon itself. In other words, wave/ wind statistics are not the only way to determine what is an extreme event.

A quick overview of the sand barriers impacted by extreme events distributed around the world highlights hundreds of interesting places that illustrate the aforementioned idea. Some striking examples are: South-Eastern U.S.A. (hurricanes), Eastern Asian coast (typhoons), ... . However, western European coast is submitted to "extreme" events also (e.g. Xinthia storm recently), as well as north-westernmost Mediterranean sea where the intensity of wind/ waves is small with respect to that observed during real hurricanes or typhoons. Nevertheless, such events have major consequences on the dynamics of sand barriers and strike the regional environment as much as a typhoon may do. Having this in mind, some questions arise: What makes an event "extreme"? What kind of impact could distinguish an "extreme" storm from a more classical one? Are there relationships between extreme wave/wind forcings and impacts on the sand barrier? All these questions are open questionings and key research topics of KUNSHEN. 


\section{XII ${ }^{\text {èmes }}$ Journées Nationales Génie Côtier - Génie Civil \\ Cherbourg, 12-14 juin 2012}

\section{Conclusion}

This paper is the presentation of the KUNSHEN project, of the field protocols, and of the morphologic and hydrodynamic settings of the Cigu system. The data processing of the first field campaign is on-going and the second field campaign will start at the beginning of summer 2012 for the typhoon season. But at this very preliminary stage of the project, the analysis of the hydro-morphodynamics of the sand barrier under extreme events seems fundamental for us as it questions the meaning of the term "extreme event". We are now going (a) to fully process the data from the winter field survey, (b) to achieve summer field survey and (c) to combine the results of field surveys together with theoretical physics, numerical modelling and physical experimentation.

\section{References}

LIN T.-Y., LO Y.-F., HUNG C.-Y. (2007). Geomorphic changes on the barrier islands of southwestern Taiwan. Proceedings of the 29th Ocean Engineering Conference in Taiwan, 433-438. (in Chinese with English abstract).

LIU P.C., CHEN H.S., DOONG D.-J., KAO C.C., HSU Y.-J.G. (2008). Monstrous ocean waves during Typhoon Krosa. Annales Geophysicae 26, pp 1327-1329. doi:10.5194/angeo-26-1327-2008 
Thème 2 - Dynamique sédimentaire 